\title{
The 7 Habits of Highly Effective Rounding
}

$\mathrm{I}$ n this issue of the Journal of Graduate Medical Education, Sandhu et $\mathrm{al}^{1}$ evaluate the differences between highly effective and low-yield family-centered bedside rounds. The "manager," or rounds leader, must engage in a high level of planning and collaboration, and the leader's managerial skills were found to be crucial to creating a successful educational experience for the team. Where are these skills taught in a typical residency curriculum? They are not explicitly mentioned in the Accreditation Council for Graduate Medical Education core competencies, although it could be argued that practice-based learning, systems-based practice, and communication skills are all part of the skills set of an effective manager. ${ }^{2}$ Pilot projects have sought to prepare residents for the real world after residency, ${ }^{3}$ but they have not been systematically incorporated on a national level. In Canada, the site of this study, the 7 CanMEDS competencies are used to assess trainees, with 1 of these encompassing the role of manager. ${ }^{4}$ However, it is not clear that the importance of the manager's role is widely recognized in all settings. When asked to rate the importance of the CanMEDS' manager role, Danish residents ranked it lower for outpatient versus inpatient specialties. ${ }^{5}$

Managerial skills often are taught through an "informal curriculum," the intentional or unintentional example set by the attending physician or senior resident leading rounds. ${ }^{6}$ Steven Covey's Seven Habits of Highly Effective People was the first of many best-selling management books offering self-management strategies. Covey's work has long been thought to have practical applications in systems improvement, ${ }^{8}$ including that in health care.

We offer evidence from the literature in business management, ${ }^{9}$ as well as medicine, using Covey's 7 habits as a framework for conducting effective family-centered bedside rounds. The aim is to emphasize practices that likely will serve physicians well in the management of medicine as well as in their personal lives.

Daniel A. Handel, MD, MPH, is Associate Professor of Emergency Medicine and Vice Chair and Clinical Director, Department of Emergency Medicine, Oregon Health and Science University; and Nicole A. Steckler, PhD, is Associate Professor of Management, School of Medicine, Oregon Health and Science University.

Corresponding author: Daniel A. Handel, MD, MPH, Oregon Health and Science University, 3181 SW Sam Jackson Park Road, Mail Code: CDW-EM, Portland, OR 97239, handeld@ohsu.edu

DOI: http://dx.doi.org/10.4300/JGME-D-13-00316.1

\section{Habit 1: Be Proactive}

The guiding principle of family-centered care is to anticipate needs and problems so they can be addressed before getting worse. This requires proactive engagement from every member of the team, including attending physicians, residents, students, nurses, family, and patient. While not mentioned in the study by Sandhu et al, ${ }^{1}$ this is also an opportunity for the nurses and other health professionals to participate and provide valuable, unique insights. In 1 study in a pediatric population, early clinician engagement and improved multidisciplinary communication led to a reduction of greater than $50 \%$ in adverse drug reactions. ${ }^{10}$

\section{Habit 2: Begin With the End in Mind}

Leaders, whether attending physicians or senior residents, should have an idea of what they hope to accomplish each day. Leaders on rounds also should have at least a general familiarity with each patient's condition prior to rounds, allowing them to guide learners and families. The plan should include setting a target for when rounds will conclude and the time available for each patient encounter, which will depend on the number of patients on the service. On busier days, a more streamlined approach is warranted; by setting goals for each encounter, lengthy conversations with families can be minimized. One study found that a lean, focused, patient-centric rounding structure not only increased patient and staff satisfaction but also improved patient throughput and decreased attending physicians' hours used. ${ }^{11}$ Lean and six-sigma methods ${ }^{12}$ have also been used to streamline rounding by standardizing practices and eliminating nonessential activities such as "pre-rounding." 13,14

\section{Habit 3: Put First Things First}

Time management was cited by Sandhu et $\mathrm{al}^{1}$ as an important educational component of family-centered bedside rounds. A key component of time management is prioritizing important tasks. The leader should prioritize the order of patients during rounds by seeing patients who are waiting for the team's action first, such as patients who are ready for discharge or waiting for time-sensitive tests to be ordered or who need team assessment to determine the next step in their care. This allows team members to initiate important decisions sooner and thereby improve patient throughput and quality of care. Articulating why patients are being seen in a particular order also teaches learners how to prioritize patient care, a valuable skill for their future careers. 


\section{Habit 4: Think Win-Win}

Sandhu et $\mathrm{al}^{1}$ identify competing patient care and educational priorities as a contributing factor to the educational success of family-centered bedside rounds. In order to optimize both the learner's educational experience and the patient's quality of care, leaders should seek mutually beneficial "win-win" solutions as an effective strategy to balance competing priorities. Leaders must help learners solicit knowledge about the patient and medical practice while not undermining the patient's confidence in the learner's skills once the leader leaves. Initial inquiries from the leader should start with general questions and increase in detail and complexity based on the learner's responses. If constructive feedback to the learner is needed, this should be given later and in private.

\section{Habit 5: Seek First to Understand, Then to Be Understood}

After setting the tone and time frame for the patient encounter, the leader should remain quiet while the team presents the case. Any questions should be succinct to gain better understanding as well as demonstrate the leader's interest and engagement in the presentation. Prior review of the patient's chart will help the leader anticipate important questions.

Once the team proposes an initial plan, the leader can help tailor it to meet patient and family needs. By explaining why changes are needed, the leader will further educate participants in the clinical reasoning process and underlying science.

\section{Habit 6: Synergize}

Improved patient health depends on active participation by all team members. For this reason, subtle discoveries by each team and family member should be celebrated. Each piece of data can have a profound impact on patient outcomes. When the leader invites and explicitly acknowledges input, it creates a positive feedback loop, encouraging future team participation and thereby improving the level of care. ${ }^{15}$ Several studies have demonstrated that interdisciplinary rounds improve learning and quality of care. ${ }^{16-19}$ Currently, this is not standard practice. ${ }^{20}$

\section{Habit 7: Sharpen the Saw}

The leader should explicitly set aside time daily or weekly to debrief with the team to discuss how rounds went and how they can be improved, which should include requesting feedback about the leader's own organization of the process. By using the feedback to improve future rounds, the leader models commitment to lifelong learning and interest in improving the experience for all involved.
Management strategies have traditionally been considered less relevant to medical education and more applicable to the business world, yet the management processes and practices used by attending physicians and senior residents are a valuable implicit part of the curriculum, whether intended or not. Consistent modeling of skillful daily rounds management by medical leaders can prepare learners to manage their own practice of medicine most effectively.

\section{References}

1 Sandhu AK, Amin HJ, McLaughlin K, Lockyer J. Leading educationally effective family centered bedside ward rounds: it's about management. J Grad Med Educ. 2013:5(4):594-599.

2 Nissen K, Angus SV, Miller W, Silverman AR. Teaching risk management: addressing ACGME core competencies. J Grad Med Educ. 2010;2(4):589-594.

3 Hanna WC, Mulder DS, Fried GM, Elhilali MM, Khwaja KA. Training future surgeons for management roles: the resident-surgeon-manager conference. Arch Surg. 2012;147(10):940-944.

4 Chou S, Cole G, McLaughlin K, Lockyer J. CanMEDS evaluation in Canadian postgraduate training programmes: tools used and programme director satisfaction. Med Educ. 2008;42(9):879-886.

5 Ringsted C, Hansen TL, Davis D, Scherpbier A. Are some of the challenging aspects of the CanMEDS roles valid outside Canada? Med Educ 2006;40(8):807-815.

6 Stern DT. In search of the informal curriculum: when and where professional values are taught. Acad Med. 1998:73(suppl 10):28-30.

7 Covey SR. Seven Habits of Highly Effective People. New York: Free Press; 1989.

8 Haimes YY, Schneiter C. Covey's seven habits and the systems approach: a comparative analysis. IEEE Trans Syst Man Cybern A Syst Hum. $1996 ; 26(4): 483$

9 Pfeffer J, Sutton RI. Evidence-based management. Harvard Business Review, 2006.

10 Gazarian M, Graudins LV. Long-term reduction in adverse drug events: an evidence-based improvement model. Pediatrics. 2012;129(5):e1334-e1342

11 Vats A, Goin KH, Villarreal MC, Yilmaz T, Fortenberry JD, Keskinocak P. The impact of a lean rounding process in a pediatric intensive care unit. Crit Care Med. 2012;40(2):608-617.

12 Glasgow JM, Scott-Caziewell JR, Kaboli PJ. Guiding inpatient quality improvement: a systematic review of Lean and Six Sigma. Jt Comm J Qual Patient Saf. 2010;36(12):533-540.

13 Chand DV. Observational study using the tools of lean six sigma to improve the efficiency of the resident rounding process. J Grad Med Educ 2011;3(2):144-150

14 Vats A, Goin KH, Fortenberry JD. Lean analysis of a pediatric intensive care unit physician group rounding process to identify inefficiencies and opportunities for improvement. Pediatr Crit Care Med. 2011;12(4):415-421.

15 Edmondson A. Speaking up in the operating room: how team leaders promote learning in interdisciplinary action teams. Journal of Management Studies. 2003;40(6):1419-1452.

16 Cardarelli M, Vaidya V, Conway D, Jarin J, Xiao Y. Dissecting multidisciplinary cardiac surgery rounds. Ann Thorac Surg. 2009;88(3):809-813.

17 Shrader S, McRae L, King WM, Kern D. A simulated interprofessional rounding experience in a clinical assessment course. Am J Pharm Educ 2011;75(4):61.

18 Bharwani AM, Harris CG, Southwick FS. Perspective: a business school view of medical interprofessional rounds: transforming rounding groups into rounding teams. Acad Med. 2012;87(12):1768-1771.

19 Hoke N, Falk S. Interdisciplinary rounds in the postanesthesia care unit: a new perioperative paradigm. Anesthesiol Clin. 2012;30(3):427-431.

20 Stickrath C, Noble M, Prochazka A, Anderson M, Griffiths M, Manheim J, et al. Attending rounds in the current era: what is and is not happening. JAMA Intern Med. 2013;173(12):1084-1089. 